\title{
Elaborating a people-centered approach to understanding sustainable livelihoods under climate and environmental change: Thang Binh District, Quang Nam Province, Vietnam
}

\author{
Leslie Mabon ${ }^{1}$ - Nguyen Song Tung ${ }^{2} \cdot$ Pham Thi Tram $^{2} \cdot$ Tran Thi Tuyet $^{2} \cdot$ Le Hong Ngoc $^{2} \cdot$ Doan Thi Thu Huong $^{2}$. \\ Hoang Thi Ngoc Ha ${ }^{3}$. Natascha Mueller-Hirth ${ }^{4}$. Stephen Vertigans ${ }^{4}$
}

Received: 29 August 2019 / Accepted: 2 September 2020 / Published online: 14 October 2020

(c) The Author(s) 2020

\begin{abstract}
This paper explores the maintenance of livelihoods under climate, environmental, and economic development pressures, through the case of Thang Binh District in Quang Nam Province, Vietnam. Within widespread recognition of the need to link sustainable livelihoods approaches with climate change adaptation, there is growing awareness of the importance of peoplecentered approaches which keep the diverse experience, capabilities, and knowledges of the most vulnerable at the heart of sustainable livelihoods thinking. In response, this paper explores the conditions for changes in modes of livelihoods in a case study area where top-down strategies for sustainable livelihoods are met with residents' diverse experiences of vulnerability, and where climate and environmental changes shape residents' relations with the landscape. The research is undertaken via interviews with residents, farmers/fishers, and local government officials. Our study finds that whilst government-led initiatives for sustainable livelihoods are welcomed in the locality, inflexible policies can make it challenging for the most vulnerable people to access support. Moreover, residents see the capacity to live with and respond to extreme weather events as a critical component of maintaining a sustainable livelihood. Our findings reinforce international literature, showing that 'the poor' are not a homogenous category, and illustrate the importance of attention to the smallest levels of government who are tasked with putting sustainable livelihoods initiatives into practice in relation to people's daily lives.
\end{abstract}

Keywords Climate change $\cdot$ Coastal communities · Quang Nam Province $\cdot$ Sustainable livelihoods $\cdot$ Vietnam

\section{Introduction}

Handled by Fabrice Renaud, School of Interdisciplinary Studies, University of Glasgow, UK.

Electronic supplementary material The online version of this article (https://doi.org/10.1007/s11625-020-00861-3) contains supplementary material, which is available to authorized users.

Leslie Mabon

leslie.mabon@sams.ac.uk

1 Scottish Association for Marine Science-University of the Highlands and Islands, Oban PA37 1QA, Scotland, UK

2 Institute of Human Geography, Vietnam Academy of Social Sciences, 1 Lieu Giai, Ba Dinh District, Hanoi, Vietnam

3 Center for Eco-Community Development (ECODE), 101-B6, Khuong Trung, Thanh Xuan District, Hanoi, Vietnam

4 School of Applied Social Studies, Robert Gordon University, Aberdeen AB10 7QG, Scotland, UK
There is widespread recognition that, with the poorest and most vulnerable people and places being hit first and hardest by climate change, approaches to sustainable livelihoods need to link with climate change adaptation (Clay 2018; Davies et al. 2013). Yet, scholars also argue that people's diverse experiences of livelihood maintenance within a locality, as well as their own knowledges and capacities to act, must not be overlooked amongst the techno-scientific data and systems thinking-driven approaches that are required to envision sustainable livelihood models under additional climate and environmental stresses (Lin and Liu 2016; Tanner et al. 2015; Tran and James 2017). This paper responds to this interest in people-centered approaches to sustainable livelihoods under climate and environmental change through evaluation of the conditions for changes in modes of livelihoods in Thang Binh District, Quang Nam Province, Vietnam. Through interview research with local 
governments, farmers, fishers, and residents in Thang Binh, we assess experiences of livelihood maintenance in an area facing both rapid economic development and increasing climate and environmental stresses. Our findings make a contribution to the existing literature on people-centered approaches by highlighting three areas of attention: who within a community is considered 'vulnerable' and how are they defined; how people's own knowledges and experiences of living with climate and environmental change as part of a sustainable livelihood mesh with techno-scientific understandings of risks to livelihoods; and the roles and limitations of the smallest scales of government in putting livelihood transitions and transformations into action.

\section{Background and context}

\section{Sustainable livelihoods under climate change pressures}

This paper explores issues around the maintenance of livelihoods under environmental, economic, and social changes, focusing on a coastal zone setting in a middle-income country. In coastal areas, climate threats may be more immediate and urgent when compared to inland areas (McGranahan et al. 2007). Yet, in low- and middle-income countries, poverty alleviation is an additional, urgent pressure in addition to climate change imperatives, and may be accompanied by nationally led development goals (Roberts 2010). Colonial histories, and an associated lack of investment in technology and infrastructure compared to the Global North, can lead to a lack of environmental data and skills to address complex socio-environmental issues (Nightingale et al. 2019; Shih et al. 2020). These concomitant social, economic, and environmental pressures can force decision-makers towards pragmatic shorter-term outcomes which balance climate and socio-economic development imperatives (Sarkki et al. 2017).

Partly as a means of balancing these pressures, sustainable livelihood approaches are increasingly being linked with climate change adaptation. The idea of sustainable livelihoods has long been used in the context of rural areas, especially in low- and middle-income countries (Bebbington 1999; Scoones 1998). Lu and Lora-Wainwright (2014) explain that sustainable livelihoods are an organising concept for understanding livelihood strategies and outcomes, one which emphasises rural people's views of their lives and the environment they live in and pays attention to livelihood resources, access to different kinds of capital, and broader institutional factors.

More recent work has, however, made explicit links between sustainable livelihoods and adaptation to climate change. Davies et al. (2013) hold that thinking about responses to climate change in terms of sustainable livelihoods can help to imagine longer term transformations for climate- and disaster-resilient livelihoods, rather than only short-term coping strategies for shocks and stresses. Clay (2018:14), arguing for stronger integration of sustainable livelihoods and climate change adaptation, similarly believes that thinking in terms of livelihoods-that is, "everyday tasks that people do and how those articulate with social, environmental and institutional contexts"- can help to visualise and make sense of complex pathways to climate change adaptation. It is also argued that in a crowded field of competing actors and techno-scientific data which tends towards systems-thinking approaches to complex climate change and sustainability problems, thinking in terms of livelihoods can help to keep the focus on outcomes that support the poorest and most vulnerable (Tanner et al. 2015).

The maintenance of livelihoods is thus argued to be a helpful lens through which to consider localised responses to multiple economic, environmental, and climate pressures. What such sustainable livelihoods look like and how they might be achieved is, however, less clear. Cannon (2013) argues that sustainable livelihoods need to shift people away from climate-dependent livelihoods (for example, agriculture and fisheries) and into alternative modes supported by top-down initiatives including social protection, insurance, and retraining. Environmental and climate changes place increasing pressure on communities' and households' livelihoods, even as adaptive actions are being taken (Biggs et al. 2018; Tran and James 2017). Yet, scholarship also suggests that community-level actions-and some aspects of climate-dependent livelihoods - can in themselves be a source of strength in imagining and enacting sustainable futures for a locality. Attention to these 'bottom-up' factors may uncover motivations for change from the personal level (Nguyen et al. 2019); take advantage of indigenous knowledge and traditional practices that can support communities in the face of shocks and stresses (Biggs et al. 2018; Lin and Liu 2016); and strengthen cultural confidence while uncovering possible synergies between environmental protection and traditional practices (Lin and Chang 2013). It is also important to acknowledge, however, that already wealthier or more educated households may have more ability to diversify their livelihoods and remain in their communities, rather than depending on subsistence or migrating to urban areas (Tran and James 2017).

\section{Aims and objectives}

The overall aim of this paper is hence to explore the conditions for changes in modes of livelihoods in a Vietnamese coastal commune facing rapid economic development and top-down sustainable livelihood strategies, where residents have their own understandings of and relations with the 
landscape, and where climate and environmental changes are informing residents' relations with the land. We speak in particular to the idea that people understand sustainability, and climate and environmental change, in relation to wider narratives of their lives and relation with the local environment in which they live (Borie et al. 2019; Dahlstrom 2014). We follow the ethos of Ayeb-Karlsson (2016: 680) and provide a "qualitative, people-centred perspective on climate change, environmental stress, and livelihood resilience" that makes a contribution to the existing literature by illustrating how sustainable livelihood transitions and transformations are understood and experienced by the people such initiatives ought to benefit. Specifically, we:

(a) clarify challenges for sustainable livelihoods in the case study area;

(b) understand top-down and 'official' responses to sustainable livelihoods under climate and environmental change in Thang Binh District, and how these are viewed by residents;

(c) evaluate less formal community or household strategies towards the maintenance of livelihoods under overarching climate, environmental, and economic development pressures in Thang Binh District.

It is also important to acknowledge that whilst the focus of this paper is not resilience per se, Dunning (2020) argues that it is impossible to discuss complexity, vulnerability, adaptive management, integration, and participation in a coastal context without also considering resilience. In places where we refer to resilience, we therefore mean the capacity of individuals, households, or communities to absorb disturbances and adapt to changes to maintain functions (Walker 2020). A table of key terms and how we interpret them is included in Table 1.

\section{Study area}

\section{Quang Nam Province}

The study area is Thang Binh District, Quang Nam Province, Vietnam. Quang Nam Province (see Figs. 1 and 2) is located on the south central coast of Vietnam, and along with other coastal provinces of Vietnam has been assessed as being at high risk from sea-level rise and extreme events such as flooding and storm surges associated with climate change (IPCC 2018; United Nations Development Programme 2019). The coastal area of Quang Nam is influenced by typhoons, tropical depressions, flooding, droughts, saline intrusion, and coastal erosion (Viet et al. 2017). In recent years, due to the impact of climate change and socio-economic development patterns, floods and droughts in the area have increased (Vu and Hoang 2013). According to Quang Nam's Action Plan to Respond to Climate Change, under a range of scenarios to 2030, most of Quang Nam Province's low-lying coastal communes will be subject to flooding and storms, and up to $30 \%$ of the total area could be affected by saline water by the 2020s (DANIDA 2013; Quang Nam Province 2013). This puts most sectors and socio-economic activities at risk from climate change, especially agriculture, tourism, and fisheries (Quang Nam Province 2013).

\section{Thang Binh District}

Thang Binh District is located in the middle of Quang Nam Province (see Fig. 2). This study focuses in particular on the coastal areas of Thang Binh District (see Fig. 3), which cover about two-fifths of Thang Binh's total area with $25 \mathrm{~km}$ of coastline running along 4 coastal communes: Binh Duong, Binh Minh, Binh Hai, and Binh Nam. In the UNDP Vietnam Climate Risk Index (2019), Thang Binh District has been rated 'very high' risk for storm hazard and superstorm surge; 'high' risk for flood hazard; and 'high risk' for annual rainfall change under the IPCC RCP8.5 (business as usual) scenario by 2050 (UNDP 2019). Due to the presence of a large river, flat land, and proximity to the sea, these four coastal communes are at particular risk from climate-related hazards. This easternmost part of the district-located on both sides of the Truong Giang River-is a coastal area, with a flat coastline and extensive beach and sand dune landscape. Although this area is a strip of land between the river and sea, due to the lakes and rivers, people have settled there for a long time, with livelihoods based on fishing as well as agriculture, aquaculture, and trading. Thang Binh District is currently implementing a new programme, targeted in particular at farmers and rural areas, under the Government of Vietnam's National Target Programme on New Rural Development. This programme aims to shift the economic structure of Thang Binh towards increasing the proportion of construction industry, trade, and services; and raising the efficiency of agricultural production. Ten industrial clusters have also been planned, six at a detailed stage of planning (Quang Nam Province 2018).

There has been investment in Thang Binh District into climate change adaptation measures. These include the construction of dams to prevent saline intrusion of high tide and sea-level rise; building drainage canal systems to reduce flood risk; construction of pumping stations to supply water for rice and other crops when irrigation water is lacking; and consolidation of agriculture and drainage systems to adapt to saline intrusion. Such investment has come from the province and state level within Vietnam, as well as from international aid organisations including the Danish International Development Agency (see, e.g., DANIDA 2013). Quang Nam Province and Thang Binh District are listed as 


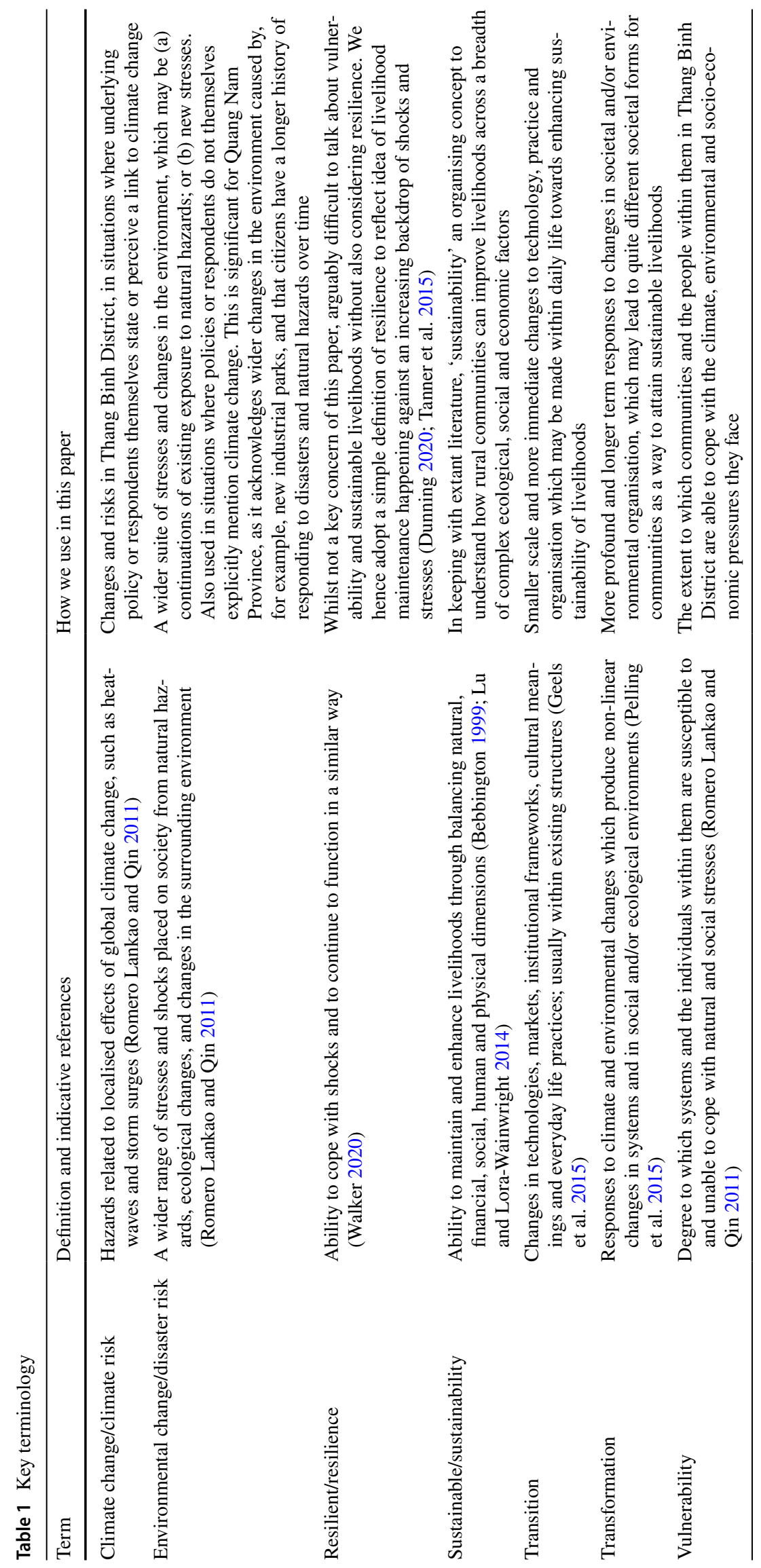




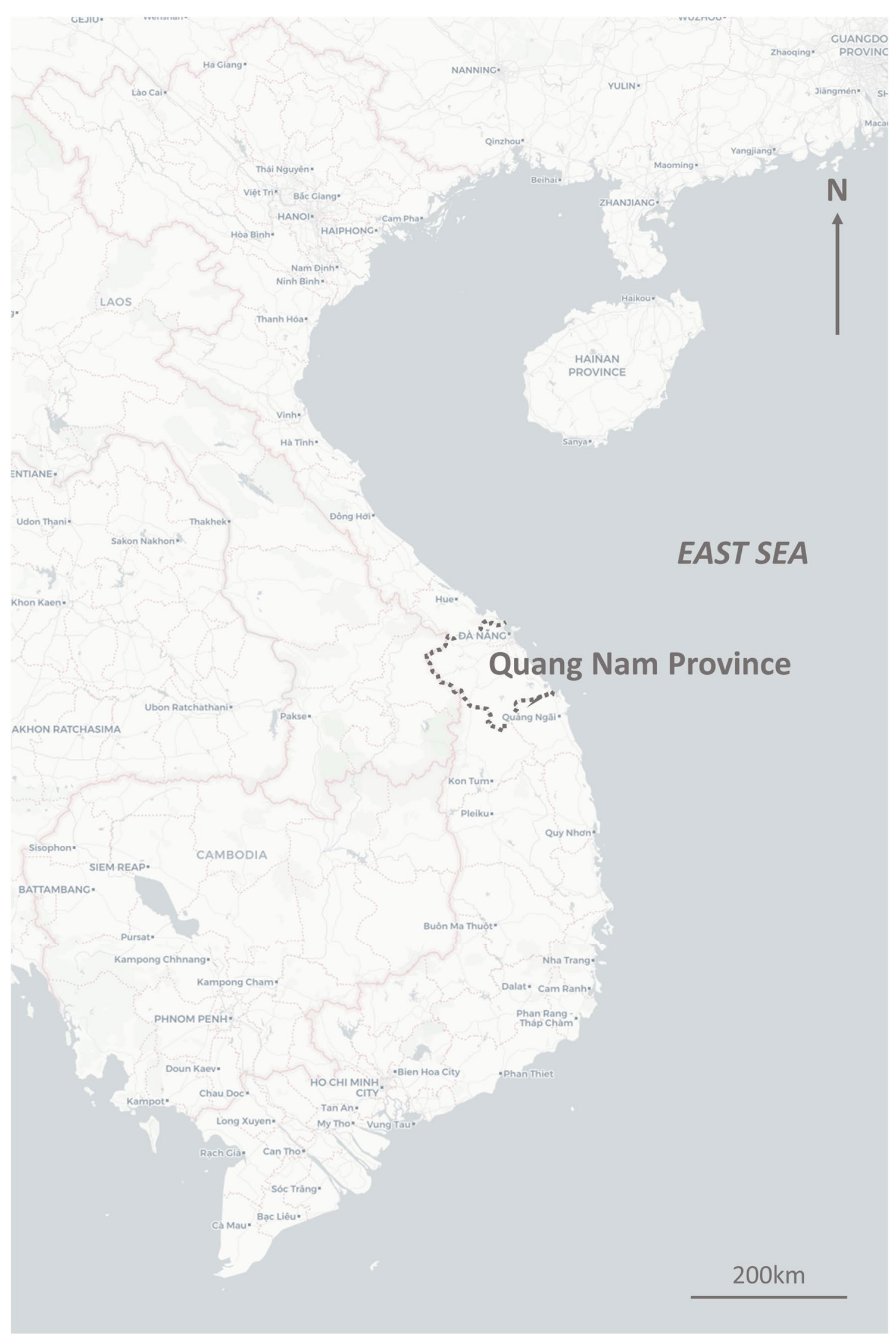

Fig. 1 Location of Quang Nam Province in Vietnam (source: adapted from map tiles by Stamen Design, under CC BY 3.0. Data by CartoDB and OpenStreetMap, under ODbL) 


\section{ADMINISTRATIVE MAP OF QUANG NAM PROVINCE}

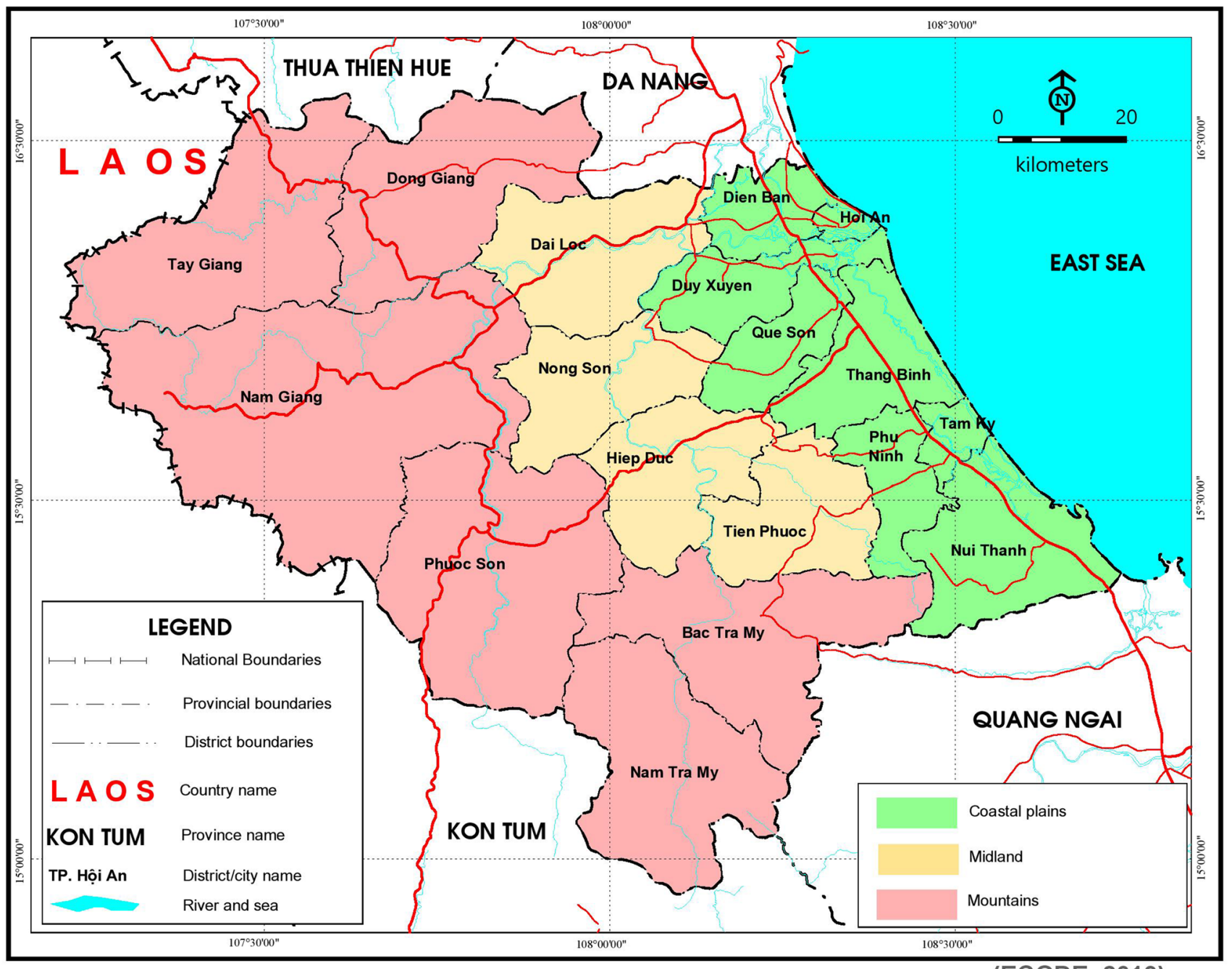

(ECODE, 2019)

Fig. 2 Map of Quang Nam Province (source: created by authors)

priority one areas by the Vietnamese government for projects and research into climate change, including international cooperation (interview 1, DPI, Quang Nam Province; interview 2, DARD, Thang Binh District) (Fig. 3).

\section{Method}

As a single case study (Yin 1984), this paper primarily makes a contribution to the existing theory on sustainable livelihoods in relation to climate and environmental change. As a coastal district facing both climate and economic development pressures, Thang Binh and the wider Quang Nam area is a useful case study to explore the maintenance of livelihoods in times of environmental, economic, and social changes. As laid out in the "Background and context", in this paper, we understand livelihoods and their relation to climate change adaptation through people's everyday tasks and their relation to social, environmental, and institutional contexts (Clay 2018), taking a qualitative and people-centred approach (Ayeb-Karlsson et al. 2016). Within this methodological tradition, the quality of research is assessed in relation to its rigour (i.e., justification of sampling strategy, connection to underpinning conceptual basis) as opposed to the language of validity and representativeness associated with positivist research (Teel et al. 2018). Accordingly, this section sets out the process through which the research was undertaken.

Data were collected through in-depth interviews conducted on the coast of Quang Nam Province in summer 2019. Given the complexity of the topic and the importance of narrative context outlined above, a grounded theory-type approach to data collection and analysis was 


\section{ADMINISTRATIVE MAP OF THANG BINH DISTRICT}

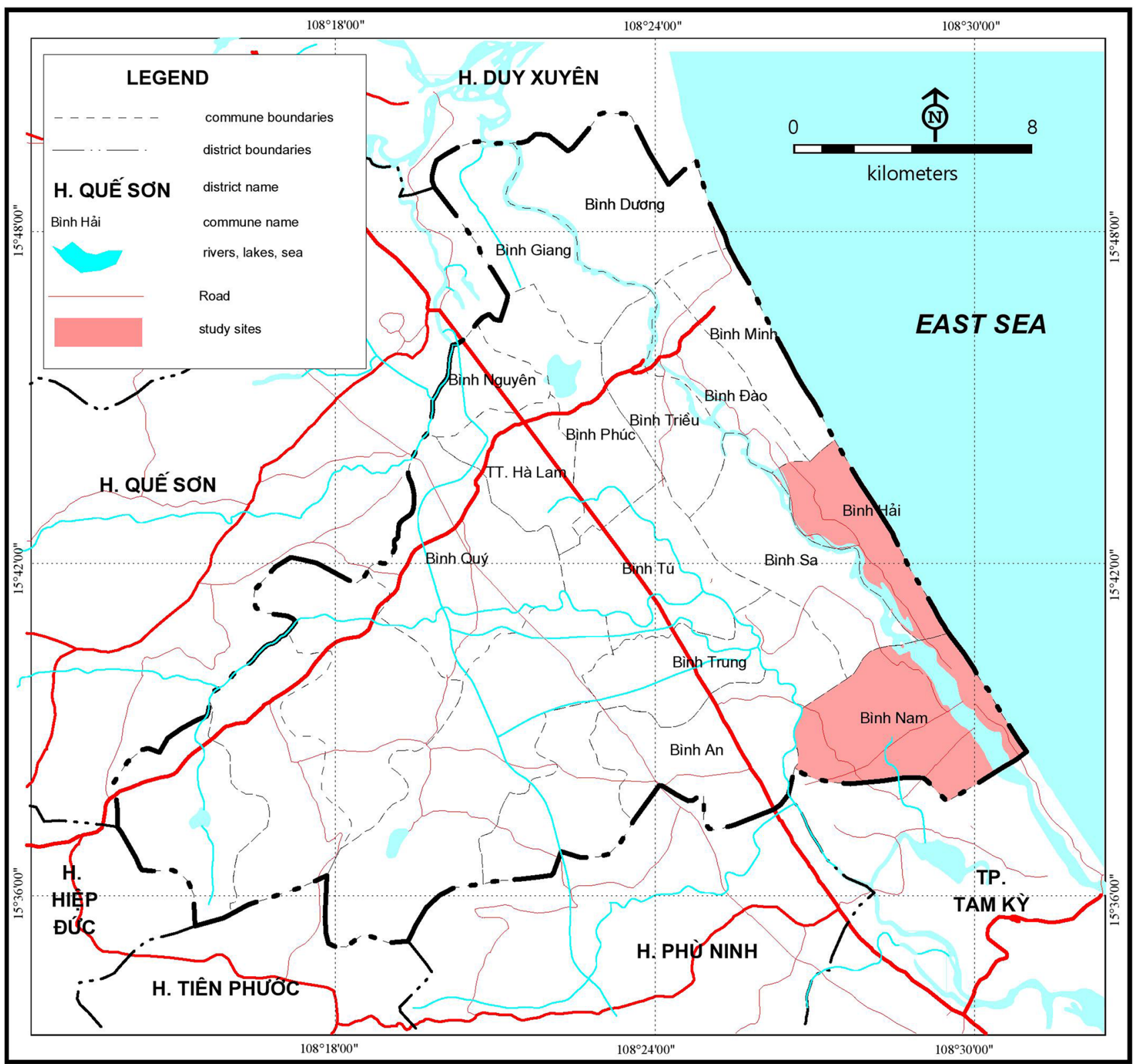

(ECODE, 2019)

Fig. 3 Map of Thang Binh District (source: created by authors)

followed. Similar to the previous research into the social dimensions of sustainability, climate and environmental change and/or coastal regions (e.g., Yuill et al. 2019), a grounded-type approach was used in this study to allow issues which respondents themselves deemed to be of importance to be identified, rather than imposing an a priori analytical framework. As per Biagini et al. (2014) and Hopkins et al. (2016), however, given that this study aims to refine and develop the existing conceptual work on sustainable livelihoods under climate and environmental pressures, the grounded approach was used only to allow interpretative flexibility during data collection and analysis. In other words, the themes and ideas identified during analysis were ultimately fed back into existing conceptual work on sustainable livelihoods and climate change adaptation, rather than building new theories from the ground up in the way one would expect from a strict grounded theory approach (Strauss and Corbin 1994). 
The broad topic of the research-sustainability in livelihoods under climate and environmental change for rural coastal communities in a specific district-was developed through review of existing scholarly literature to set the study objectives. Specific areas of questioning were then clarified through discussion within the research team (the question schedule is included as Supplementary Material 1). Following the grounded type-approach outlined above, analysis was conducted through a structured workshop involving all research team members. Insights gained from the interviews were grouped into themes through an iterative discussion-based process, with themes and clusters refined until all team members were in agreement. Supplementary Material 2 shows the thematic 'map' produced through this analytical process.

In total, 50 people were interviewed across 14 interviews (Table 2). Interviewees were selected to cover (a) the different levels of government within the coastal areas of Thang Binh District (province, district, and commune) responsible for setting and enacting policy relevant to livelihoods, sustainability, and climate and environmental change; and (b) citizens living in coastal communes assessed at being at high climate and disaster risk (UNDP 2019) and working in sectors (agriculture and fisheries) identified at being at risk within Quang Nam Province's action plan on climate change (Quang Nam Province 2013). Given the strong emphasis in the literature on gender differences in vulnerability (e.g., Goldin et al. 2019), particular attention was paid to ensuring female respondents were represented at commune level.
It is important to acknowledge the power relations and cultural differences within the research team. The research team comprised a mixture of academics working at 'Western' institutions, and Vietnamese researchers from academic institutions and NGOs. Reflecting wider trends within social science, reflexivity around decolonising methodologies, and fostering collaborative research practices across different knowledge systems (Zanotti and Palomino-Schalscha 2016) were hence of the utmost importance. The research team attempted to address this imperative through collaborative refinement of both the research questions and analytical themes in structured workshop-type settings before and after entering the field. Reflecting the observations of Fuhrmann and Schiele (2017) on undertaking transcultural research in Vietnam, such collaboration also entailed sensitivity to Vietnamese research norms (e.g., note-taking rather than audio-recording) and the production of a detailed and structured interview schedule to reconcile the desire for open-ended discussion-type questions with the more structured questioning usually undertaken in Vietnam. In line with administrative regulations in Vietnam, the provincial, district, and commune People's Committees also had to be contacted for permission to conduct research. Whilst this inevitably influences the kind of research that can be conducted, the research team worked to develop areas of questioning focusing on knowledge, policies, and experiences of climate and environmental change, that did not address topics of a highly contentious nature yet would still allow academically meaningful insights to be gained on resilient

Table 2 Information on interviewees

\begin{tabular}{|c|c|c|c|}
\hline $\begin{array}{l}\text { Inter- } \\
\text { view } \\
\text { number }\end{array}$ & Interviewee(s) & Location & $\begin{array}{l}\text { Number of } \\
\text { people inter- } \\
\text { viewed }\end{array}$ \\
\hline 1 & $\begin{array}{l}\text { Quang Nam Provincial People's Committee Department of Agriculture and Rural Develop- } \\
\text { ment (1 male); Department of Labour, Invalids and Social Affairs ( } 2 \text { male); Department of } \\
\text { Planning and Investment (1 female); Department of Natural Resources and Environment (1 } \\
\text { male) }\end{array}$ & Tam Ky City & 5 \\
\hline 2 & $\begin{array}{l}\text { Thang Binh District People's Committee, Department of Agriculture and Rural Develop- } \\
\text { ment ( } 3 \text { male) }\end{array}$ & Ha Lam Town & 3 \\
\hline 3 & Binh Hai Commune People's Committee, Chair and Vice-Chair (2 male) & Binh Hai Commune & 2 \\
\hline 4 & Binh Nam Commune People's Committee, Chair and Vice-Chair (2 male) & Binh Nam Commune & 2 \\
\hline 5 & Farmers ( 7 female, 1 male) & Binh Hai Commune & 8 \\
\hline 6 & Farmers (6) and fisher (2) (2 female, 6 male) & Binh Hai Commune & 8 \\
\hline 7 & Farmers (6) and fishers (1) (0 female, 7 male) & Binh Hai Commune & 7 \\
\hline 8 & Farmers ( 7 female, 0 male) & Binh Hai Commune & 7 \\
\hline 9 & People's committee employees ( 2 female) & Binh Nam Commune & 2 \\
\hline 10 & Farmer (1 female) & Binh Nam Commune & 1 \\
\hline 11 & Fisher (1 male) & Binh Nam Commune & 1 \\
\hline 12 & Farmer (1 female) & Binh Nam Commune & 1 \\
\hline 13 & Farmers ( 2 female $)$ & Binh Nam Commune & 2 \\
\hline 14 & Stallholder/former farmer ( 1 female) & Binh Nam Commune & 1 \\
\hline
\end{tabular}


and sustainable livelihood challenges under climate and environmental change. All interviews were undertaken in Vietnamese and led by a Vietnamese member of the research team. In the field, the research team divided into sub-groups of 3 people, with a second Vietnamese researcher with good English capability interpreting and a UK-based researcher asking follow-up questions thereafter.

\section{Findings}

We structure the Findings around the three aims laid out in the "Background and context": to clarify challenges for sustainable livelihoods in the case study area; to understand top-down and 'official' responses to sustainable livelihoods under climate and environmental change, and how these are viewed by residents; and to evaluate less formal community or household strategies towards the maintenance of livelihoods under overarching climate, environmental, and economic development pressures.

\section{What are some of the challenges to sustainable livelihoods on the Thang Binh coast?}

Given the interest of this paper in sustainable livelihoods, Table 3 provides a qualitative overview of livelihood assets in Binh Hai and Binh Nam Communes (based on information elicited in interviews) to summarise the main opportunities and challenges towards sustainable livelihoods, and provide context for the whole Findings section.

Interviewees suggested that fisheries, agriculture, and aquaculture, already precarious forms of employment, are becoming even more challenging with environmental pressures. Coastal communes face frequent coastal and river flooding from the Truong Giang River; 4-5 severe storms annually; and extreme heat which local officials believe are a result of climate change (interview 2, DARD, Thang Binh District). Extreme heat reduces the quality of farmland soil and limits the availability of irrigation water, leading to the abandonment of farmland (interview 2, DARD, Thang Binh District). Storms, meanwhile, are dangerous for fishers given the small size of their boats and reduce the number of days in which fishing can take place (interview 3, Binh Hai Commune PPC). Citizens report saltwater intrusion affecting productivity, low rice prices, and risk of crop disease, all of which create risk for households (interview 6, farmers, Binh Hai Commune).

Industrial areas and tourist resorts are being promoted on the coast as an alternative livelihood model (see Sect. 5.2). The development of such infrastructure is driven by the existing and ongoing drive for socio-economic development, with investment from national government to develop the Quang Nam coast (interview 9, Binh Nam PPC staff).
Yet, the construction of industrial and tourism infrastructure involves the removal of mangrove and land-based coastal forests, which act as an important buffer for coastal communes against flooding and storm surges (interview 4, Binh Nam Commune PPC). As climatic changes reduce the viability of citizens' traditional livelihoods in the local area, the infrastructure designed to create alternative livelihoods and reduce socio-economic vulnerability may thus have the unfortunate effect of increasing citizens' exposure to extreme events.

It is also worth noting that the techno-scientific data underpinning claims to climate change and the negative effects of infrastructure development are less clear. Respondents reported that the provincial Department of Natural Resources and Environment is in charge of collecting data on environmental change and reporting to local government (interview 1, DONRE, Quang Nam Province); and that after extreme events, data are collected by the disaster prevention committee (interview 1, DARD, Quang Nam Province). At commune level, however, both officials and citizens relied more on their own personal sense that climate was changing, sometimes having to make decisions under increasingly complex situations based on their own experience and knowledge, instead of waiting for government instructions or warnings (interview 4, Binh Nam Commune PPC).

Maintenance of livelihoods on the Thang Binh coast thus happens in a context where (a) the local effects of climate and environmental change are acknowledged by all levels of society; yet, (b) government interventions designed to enhance the sustainability of livelihoods may increase people's exposure to extreme events; and (c) specific and immediate knowledge on how climate and environmental changes are affecting society may be lacking at the lowest levels of government where actions need to be implemented.

\section{What are the top-down and 'official' responses to sustainable livelihoods under climate and environmental change, and how are these viewed by residents?}

In Thang Binh, the direction of livelihood change is from agriculture, fisheries and aquaculture, to other industries such as textiles, construction, and tourism (interview 1, DPI, Quang Nam Province; interview 2, DARD, Thang Binh District). Investment in industrial zones and tourism does create jobs viewed as attractive to those working in agriculture, aquaculture, or fisheries-to the extent that some locals actively abandon farming and fishing (interview 2, DARD, Thang Binh District). The physically challenging and in cases dangerous nature of farming and fishing work was cited by respondents as a factor encouraging them to transition to new lifestyle modes (interview 6, farmers, Binh Hai Commune; interview 14, stallholder, Binh Nam Commune); 


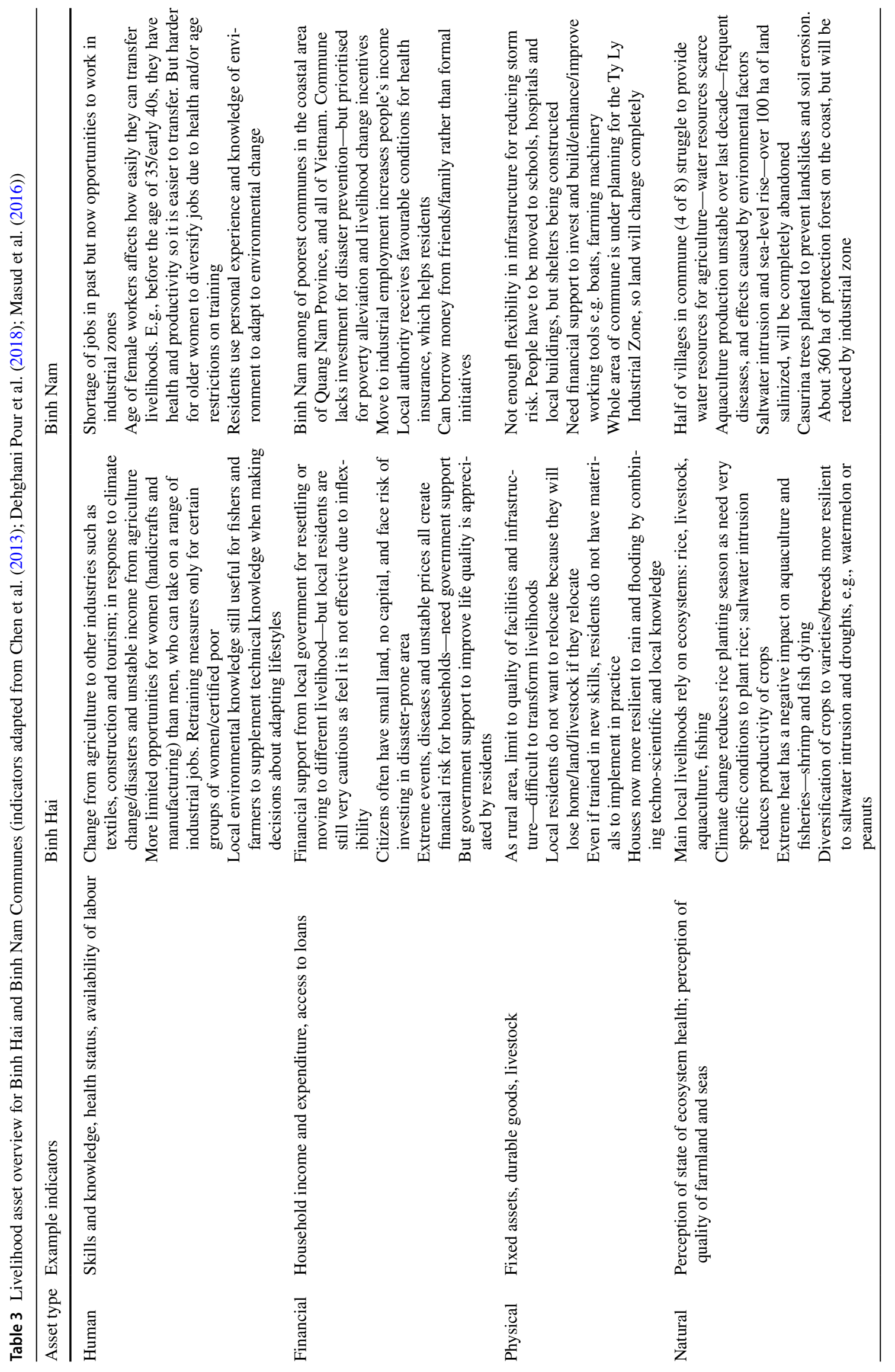


as were the effects of saltwater intrusion and sea-level rise on reducing productivity of farmland from two rice crops a year to one, and leading to abandonment (interview 4, Binh Nam PPC; interview 6, farmers, Binh Nam Commune). Even for those continuing to work in agriculture, aquaculture, and fisheries, technological improvements supported by government training can increase productivity and free up time for other income-generating activities (interview 9, Binh Nam PPC staff; interview 11, fisher, Binh Nam Commune).

Negative effects of climate change are used to justify retraining citizens for different kinds of work, particularly by higher levels of government (e.g., interview 1, DLISA, Quang Nam Province; interview 2, DARD, Thang Binh District). Citizens themselves spoke positively of the potential for livelihood transitions-both retraining into industrial/ construction work and introducing new technology into farming and fishing - to maintain productivity and reduce poverty. It was noted that lives in the community were improving because of increase in income and employment (interview 10, citizen, Binh Nam commune; interview 11, fisher, Binh Nam Commune); and that government support was welcomed in improving living standards (interview 5, farmers, Binh Hai Commune). Equally, though, climate and environmental changes in cases reduce motivation to improve agricultural productivity through technology, due to the risk of investing in a disaster-prone area for farmers who already have only small land and no capital (interview 8, farmers, Binh Hai Commune).

At the same time, however, citizens and lower levels of government argue that not everyone benefits equally from the drive for livelihood transition on the Thang Binh coast. Research elsewhere in Vietnam has shown strong agedependency in the uptake of work elsewhere, with younger people (especially men) going to factories and cities and sending remittances home (Narciso 2017) which may have both positive and negative effects on the livelihoods of those remaining in rural areas (Adger et al. 2002). These trends did not arise in the context of Thang Binh District, perhaps as a result of training courses to give younger people an opportunity to work in industrial parks or tourist areas less than $10 \mathrm{~km}$ from their home, providing a stable income and allowing them to return home daily (interview 3, Binh Hai PPC; interview 4, Binh Nam PPC). Nonetheless, especially for female workers, age affects how easily they can transition livelihood, with limited support for older women (interviews 12 and 13 with farmers, Binh Nam Commune). Women younger than 35-40 were reported to have more opportunities to participate in retraining programmes, whereas older workers face barriers due to perceived poorer health (interview 4 with Binh Nam Commune People's Committee). Thus, whilst changing social dynamics do give women a more equal say in household finances (e.g., interview 14 with stallholder, Binh Nam Commune) and whilst women 
are taking on community leadership roles in climate change training events (interview 3, Binh Hai PPC), the extent to which higher level government policy facilitates transitions to sustainable livelihoods may be open to question. A frequently cited reason for this, as we now elaborate, is the inflexibility of policy structures.

Governments at the district and commune level-by their own admission-largely have to follow directions from higher levels of government when it comes to decisions over how to facilitate sustainable livelihoods under a changing economy and environment. Definitions for who is classified as 'vulnerable' - and hence who is prioritised in livelihood transition interventions-are set by central government criteria and policies (interview 1, DPI, Quang Nam Province). Although this means that people meeting the requirement, generally those in possession of a poverty certificate, will receive priority, this system also means that there is no differentiation between different categories of vulnerable people such as women, children, or elderly (interview 1, DARD, Quang Nam Province). It has been suggested that poverty certificates are sought after due to the healthcare and education benefits which they bring, and that local government methods to determine who is allocated a poverty certificate are unreliable and subjective (Reis 2012; Roelen 2018). Indeed, whilst citizens felt that older people were affected most when disasters happened, it was not necessarily the case that such people would receive support if they were not certified as being in poverty (interview 13, farmers, Binh Nam Commune). The need to follow central government definitions and protocols makes it hard to support groups within the 'vulnerable' category - such as older women - who may need additional support.

Indeed, government officials working at the commune level highlighted the difficulties in implementing government-oriented policies and measures to maintain the sustainability of livelihoods. National government policy can be too generalised for local governments to know how to implement (interview 1, DARD, Quang Nam Province). Accessing financial support requires citizens to meet a number of criteria and follow a range of complex processes, and thereafter follow strict requirements for spending and reporting. The accompanying paperwork can be challenging for citizens who may not be familiar with complex application and reporting processes (interview 3, Binh Hai PPC). Even if support is available, constraints on usage mean that it may not be targeted towards the right actions. The Binh Hai People's Committee explained that whilst there are support policies and mechanisms, at the time of interview, the available support cannot meet the specific demands of local residents-in this case, to allow the commune to build underground storm shelters and provide swimming lessons for children (interview 4, Binh Hai PPC). Farmers too, whilst grateful for government support, felt that formal training in new techniques to boost agricultural productivity was of little value if they were not subsequently provided with resources to put such techniques into practice (interview 7, farmers, Binh Hai Commune). As such, whilst there is a breadth of policies and initiatives to enable sustainable livelihoods on the Thang Binh coast, the restrictive policy frameworks within which these are deployed can deter citizens from accessing support, and prevent decision-makers at the commune level from taking actions that they feel are appropriate to the local context.

The complex policy landscape around support for livelihood transition is further confused by external support from NGOs, charities, the private sector, and foreign state donors. Quang Nam Province has been targeted by Korean aid in particular (interview 1, DPI, Quang Nam Province); and Danish projects aimed at increasing awareness of water resources on the coast of Thang Binh (interview 2, DARD, Thang Binh District). However, local-level officials feel communication between international organisations such as the World Bank and the different levels of Vietnamese government does not reach them, with climate change impact assessments not provided to local authorities. This makes it difficult to integrate the outcomes of such projects into local policy support (interview 1, DPI, Quang Nam Province). Coordination between government sectors at provincial level can be difficult, as functions and tasks can be duplicated between different ministries and departments. Different departments report to different ministries, creating further challenges for accessing and sharing data (interview 1, DARD, Quang Nam Province).

In sum, there is at base good support-both from national government and internationally-for sustainable livelihoods on the Thang Binh coast. Yet, the rigid and bureaucratic nature of policy, dictated by higher levels of government, acts as a barrier preventing local-level decision-makers from implementing actions appropriate to their communes. This complexity may be intimidating and off-putting for citizens, particularly those who may already feel disempowered and unwilling to engage with formal support processes. The difficulty of collaborating between sectors, and of sharing information between governmental and non-governmental organisations, poses further challenges for giving the people responsible for integrating sustainable livelihoods with climate change adaptation actions the knowledge and data which they need to act.

\section{What are the less formal community or household strategies towards the maintenance of livelihoods under overarching climate, environmental, and economic development pressures?}

Given the links between sustainable livelihoods and climate change adaptation outlined in Sect. 2, it is notable 
that respondents saw the ability to be able to react to or live with extreme weather events as a core component of maintaining a sustainable livelihood. Community relations and local knowledge were seen as a source of strength in this regard. These informal aspects are significant, given the complexity of policy structures and the limits this may place on formalised processes for sustainable livelihoods outlined in Sect. 5.2.

Respondents discussed support within families and within communities as facilitating both the sustainability of livelihoods and the ability of people to withstand extreme events. In the absence of salaries or pensions, older people are supported by working children, receiving a small salary to look after grandchildren (interview 14, stallholder, Binh Nam Commune). Particularly during times of disaster, older people rely on this income for support (interview 9, People's Committee employees, Binh Nam Commune). Familial relations can also support wider livelihood transformations, an interviewed stallholder for example explaining that she used loans from family and friends to purchase a bread oven and equipment to move away from farming (interview 14, stallholder, Binh Nam Commune).

Within the wider community, people will open their homes to shelter neighbours during storms, with those on higher ground acknowledging their responsibility to take in those on lower ground during extreme events (interviews 12 and 13, farmers, Binh Nam Commune). Especially among fishers, knowledge of the marine environment and of how to respond to storms is passed down from generation to generation, sometimes supplementing or replacing more technical weather forecasting (interview 3, Binh Hai PPC). Responsibilities during disaster are also shaped by gender. Respondents note that during storms, men will stay to protect the home, but also may be exposed to higher risk through participation in fishing (interview 6, farmers, Binh Hai Commune; interview 14, stallholder, Binh Nam Commune). Conversely, as men are fishing on seas, it is mostly women who participate in climate change training activities. When disasters happen, the local women's union and the army will help those affected (interview 3, Binh Hai PPC). Both familial and community relations, and their role in keeping livelihoods going under increasing climate pressures, were discussed by citizens and community-level respondents positively, yet largely in isolation from formal government support for livelihood transitions. Community relations may thus provide an important locally appropriate supplement to top-down formal livelihood transition initiatives.

Moreover, responses indicated a certain degree of reluctance from citizens to engage with formal training sessions or initiatives. Whilst fishing boats are now legally mandated to carry radios, with support provided to allow these to be fitted, it was suggested that fishers do not listen to local radio channels and prefer to trust either their local knowledge or information from international channelswhich sometimes differ from local forecasts (interview 4, Binh Nam PPC). Citizens used their own intuition to justify their belief that storms were stronger and lasting longer, and that disasters were coming more frequently (e.g., interview 5, farmers, Binh Hai Commune; interview 14, stallholder, Binh Nam Commune). It was suggested too that as it can take time to provide information and warnings once data are collected, citizens use local knowledge and experience to sense changes in the first instance, later confirming these with 'official' information when making decisions about how to respond to a changing environment in daily life (interview 3, Binh Hai Commune PPC). Whilst Binh Hai Commune report good participation in climate change awareness sessions among women in particular, Binh Nam officials believe that citizens are anxious to join formal training sessions at People's Committee premises (interview 4, Binh Nam PPC). Trust and/or willingness to engage with formal processes to build capability in adapting to climate change as part of sustainable livelihood transitions, and especially the physical spaces in which these actions are initiated, is thus not uniform and may vary across communes and groups of people.

A final point of interest is the connectedness of citizens to their locality in spite of environmental degradation and increasing risk from extreme events. Farmers expressed pride in the characteristics of local soil and climate, which creates specific conditions for rice-planting and motivates them to continue farming (interview 7, farmers, Binh Hai Commune). Others aspired for more education and job opportunities for their children, but, at the same time, did not want to leave their home area and felt a sense of responsibility for guarding their land for subsequent generations (interview 5, farmers, Binh Hai Commune). Commune officials suggested this connectedness to land makes some citizens reluctant to be relocated to lower-risk areas, and that a perception exists of agricultural land being 'wasted' if it is sold for development but left lying fallow before construction commences (interview 3, Binh Hai PPC).

As such, whilst government-led initiatives do have a role in maintaining livelihoods under climate and environmental change, relations within communities are viewed by respondents as an additional source of strength on the way to maintaining sustainable livelihoods. This may include familial support, understandings within communes of who and where is vulnerable, local environmental knowledge, and a sense of pride in the land and locality. It is especially notable that having the capability to respond to environmental shocks and stresses is discussed as part of developing a more sustainable livelihood. Yet, residents' deep connections to the coastal environment may also reduce willingness to engage with formal information provision or relocation initiatives led by the local government. It is hence crucial 
that livelihood change models respect, and do not break or weaken, existing community relations and local environmental knowledge.

\section{Discussion}

\section{Contribution to existing research}

Our first contribution relates to clarifying enablers and barriers for sustainable livelihoods, in particular the need for critical reflection on whose livelihoods are being improved, and in what ways. Tanner et al. (2015) advocate for keeping the needs of the poorest and most vulnerable at the forefront when considering responses to increasing climate and environmental pressures. Our findings build on this point, and on other hazard and disaster research (e.g., Chang et al. 2015; Krellenberg et al. 2013; Lindley et al. 2011), by reiterating that poverty itself does not equate to vulnerability, and that different experiences and types of vulnerability require different responses. It was frequently stated that anyone classified as 'vulnerable' (usually meaning in possession of a poverty certificate) would be eligible for training and support in livelihood transition. Yet, interviews with citizens and commune officials indicate such support may be of limited value if it does not benefit particularly vulnerable sub-groups (in this case older women) or if it is inaccessible to already marginalised groups as a result of bureaucratic requirements. Furthermore, the role of Hanoi-based developers such as VinGroup in building coastal resorts in Quang Nam Province, and the emphasis on 'lower-level' jobs for local citizens, resonates with experiences in other rural coastal contexts (Lindkvist and Antelo 2007). Given the removal of coastal forests for the construction of tourist resorts and industrial parks in Thang Binh, it may even be that initiatives imposed from on high in the name of enhancing local livelihood sustainability in fact reduce citizens' ability to maintain their livelihoods by damaging part of the ecosystem which has thus far reduced exposure to extreme events. When considering new infrastructural developments in the name of locally 'sustainable' livelihoods, there is hence a need to retain healthy scepticism when assessing claims to local benefit. This is especially so when top-down policy structures and shortterm poverty considerations can make it hard for locallevel policy-makers and planners to move towards thinking about the longer term sustainability of livelihoods under climate and environmental change in the way which Davies et al. (2013) advocate.

Our second point relates to how actors at the local level understand climate and environmental change, and how this relates to their views on sustainable livelihoods. Literature at the interface of sustainable livelihoods and climate change adaptation often considers climate and environmental change as an additional pressure that needs to be factored into sustainable livelihoods thinking (Clay 2018; Tran and James 2017). The Thang Binh findings indicate that being able to respond to extreme events is not necessarily a new challenge for coastal communities, and that residents see the ability to cope with shocks and stresses as an important part of a sustainable livelihood alongside more transformational change in working and living patterns. Responses show that communities have strong local knowledge in building underground storm shelters (which were even perceived as more effective than new, formalised adaptation strategies), and in using experience to avoid storms while fishing at sea. This strong local knowledge was also reported in previous empirical research in Thang Binh District (Furu and Van 2013). However, responses from district and commune officials also note the increased frequency and intensity of heatwaves and storms are making agriculture less viable, suggesting that there are limits to existing adaptability. A further complication comes from the lack of available and understandable data at the provincial, district, and commune levels, which may limit officials' ability to understand how exactly climate change makes 'business as usual' impossible and necessitates new approaches. The Thang Binh case hence reflects extant thinking on how traditional and local environmental knowledge can enhance sustainable livelihood models by feeding in understandings of how the landscape responds to shocks and stresses (Biggs et al. 2018; Lin and Liu 2016). Our findings also, however, illustrate the importance of recognising how the severity and extent of climaterelated extreme events may exceed the limits of traditional strategies to respond to environmental shocks and maintain livelihoods. As Dunning (2020) argues, in a coastal hazards context, it is increasingly hard to talk about complexity, vulnerability, and participation-elements which feed into sustainable livelihoods as discussed in our findings-without also considering resilience. Enabling local officials and citizens to access climate data, and understand how and why new threats differ to what has gone before, is a critical component of incorporating such resilience to external shocks and stresses into sustainable livelihood strategies.

Our third and final point concerns the role of the smallest levels of government in balancing different perspectives and putting sustainable livelihood initiatives into practice 'on the ground.' As Borie et al. (2019) explain, multiple and potentially competing narratives can exist within a locality. This appears to be the case on the Thang Binh coast too. The restrictive policy frameworks reported by local governors illustrate one top-down interpretation of sustainable livelihoods for a peripheral coastal region like Thang Binh, one which hinges on relocating people away from the coast and retraining 'vulnerable' people for alternative livelihoods in industry and tourism. On the other hand, interviewed 
citizens, whilst acknowledging livelihood improvements, also note that this narrative excludes those who may be unable to retrain, and also side-lines local pride in the land and the associated desire to remain in the communes rather than relocating. It is local government officials-in this case commune officials-who have the challenging task of enacting locally appropriate strategies and attempting to engage with citizens whilst working within restrictive policy frameworks. In this way, commune-level People's Committees-and the individuals within them-act as boundary spanning organisations (Shaw et al. 2013) linking provincial and national directives with community understandings of sustainable livelihoods to implement practical actions. Yet, limited access to technical knowledge, and a lack of flexibility in policy structures, may constrain what these community-level boundary spanners can achieve in practice. Reflecting the existing research on the role of local officials in supporting rural residents to shift to sustainable and climate-resilient practices (Stigter et al. 2016; Wongnaa and Babu 2020), further attention ought to be paid to the knowledge and policy support requirements of those working at the smallest levels of government, in light of their role in bridging and balancing competing narratives of sustainable livelihoods.

\section{Recommendations}

We return to the core challenge of refining an understanding of sustainable livelihood grounded in people's daily lives, against a backdrop of climate, environmental, and economic change, and make the following policy and practice recommendations.

First is the importance of understanding community relations and the ways in which the landscape creates a sense of identity and purpose, and ensuring that policy-driven approaches to livelihood sustainability do not inadvertently damage or remove these sources of strength. Whilst a sense of identity and good relations do not outweigh the very real and severe risks posed by saltwater intrusion, storm surges and heatwaves, Sect. 5.3. in particular shows that relations to the local landscape give residents a sense of belonging and purpose, and that community relations can help to maintain livelihoods under increasing extreme events. This supports the idea of the personal or household level as a driver for livelihood maintenance (Nguyen et al. 2019) and suggests the continued importance of community-driven livelihood transformations in the face of top-down models (cf Cannon 2013).

Second is creating appropriate fora and communication channels within communities for dialogue on livelihood transitions and broader transformations. Section $5.3 \mathrm{dem}$ onstrates that whilst communication is important to raise awareness of new or enhanced risks posed by climate and environmental change, and also to understand citizens' own views on what constitutes a sustainable livelihood, there may be suspicion or anxiety towards formal engagement processes, particularly in local government spaces. Existing research similarly shows that intermediary organisations (such as local governments and NGOs) have a critical role in building trust when communities are being encouraged to introduce new skills (Bennett and Franzel 2013) or scientific knowledge (Shaw et al. 2013) into their practices.

Third and final is the need to acknowledge that different groups of people may experience vulnerability differently, and to develop policy that affords lower levels of government the flexibility to enact strategies appropriate to local differences and contexts. Section 5.2 illustrates how sustainable livelihood actions driven by higher levels of government may struggle to support all residents if local-level authorities do not have the capability to implement regulations flexibly. This finding is in-keeping with broader thinking on sustainable livelihoods, which warns against thinking of communities or areas as homogenized 'vulnerable' groups and calls for recognition of the different experiences and capacities for taking action that may exist in a locality (Ayeb-Karlsson et al. 2016; Tanner et al. 2015). An approach of this nature may be challenging in country contexts such as Vietnam where local-level action is heavily driven by central policy. However, allowing finer granularity to distinguish between different types of 'poor' or 'vulnerable' people is an important step in improving the livelihoods of those most susceptible to harm.

\section{Conclusion}

As outlined at the start of the paper, interest in linking sustainable livelihoods with climate change adaptation is tempered by the concern that technocratic and/or systems thinking-driven approaches can flatten the diversity of knowledges, experiences, and, indeed, vulnerabilities that exist in a locality. Our paper has thus sought to contribute to the interest in people-centered approaches to sustainable livelihoods under climate and environmental changes, through qualitative evaluation of residents' and local governors' experiences in Thang Binh District, Quang Nam Province, Vietnam. Our findings indicate that residents on the Thang Binh coast are working to maintain their livelihoods against a backdrop of rapid economic development led by higher levels of government and the private sector, as well as the increasing prevalence of extreme events related to climate and environmental change. Whilst state-led initiatives to transition residents to working in tourism and industrial areas are appreciated, our results also indicate that inflexibility over who is defined as eligible for government support (and how this support can be accessed) may limit the effectiveness of such schemes in maintaining livelihoods. 
Furthermore, our results also suggest that residents see the ability to respond to climate and environmental changes (especially extreme weather events) as a key component of maintaining a sustainable livelihood, but that the resources and support to respond to environmental shocks come largely from within the community and their own knowledge systems. We see these findings as contributing to the international literature on people-centered approaches to sustainable livelihoods under climate change in four ways. First, we re-emphasise the need for careful reflection on the different capabilities and experiences that exist within a locality, and the recognition that 'the poor' are not a homogenous or necessarily vulnerable group. Second, we show how local and traditional knowledges of the landscape can be a source of strength in living with extreme events, but that caution needs to be exercised to identify where and when contemporary climate change exceeds or differs from what has been experienced previously. Third, we argue for attention to the role of the smallest scales of government in putting policies into practice and engaging with residents on sustainable livelihoods. Finally, we argue for approaches to livelihood transformation which allow centrally led strategies to be applied flexibly at the community level, as a means of putting people-centered approaches to sustainable livelihoods into practice.

Acknowledgements The research on which this paper is based is a result of the project 'Sustainable livelihood adaptation to climate change of rural residents in the South Central Coast: Approach from human ecology' supported by NAFOSTED (PI Dr Nguyen Song Tung). The research is also a result of the project 'Ensuring social wellbeing in climate change adaptation through ecosystem management: sharing experiences from Vietnam and Scotland' supported by the Scottish Funding Council Global Challenges Research Fund allocation to Robert Gordon University, and by RGU's Research Investment (PI Dr Leslie Mabon). Dr Leslie Mabon participated in the writing of this paper as part of his activities as a Future Earth Coasts Fellow.

Open Access This article is licensed under a Creative Commons Attribution 4.0 International License, which permits use, sharing, adaptation, distribution and reproduction in any medium or format, as long as you give appropriate credit to the original author(s) and the source, provide a link to the Creative Commons licence, and indicate if changes were made. The images or other third party material in this article are included in the article's Creative Commons licence, unless indicated otherwise in a credit line to the material. If material is not included in the article's Creative Commons licence and your intended use is not permitted by statutory regulation or exceeds the permitted use, you will need to obtain permission directly from the copyright holder. To view a copy of this licence, visit http://creativecommons.org/licenses/by/4.0/.

\section{References}

Adger WN, Kelly PM, Winkels A, Huy LQ, Locke C (2002) Migration, remittances, livelihood trajectories, and social resilience. AMBIO 31(4):358-366. https://doi.org/10.1579/0044-7447-31.4.358
Ayeb-Karlsson S, van der Geest K, Ahmed I, Huq S, Warner K (2016) A people-centred perspective on climate change, environmental stress, and livelihood resilience in Bangladesh. Sustain Sci 11(4):679-694. https://doi.org/10.1007/s11625-016-0379-z

Bebbington A (1999) Capitals and capabilities: a framework for analyzing peasant viability, rural livelihoods and poverty. World Dev 27(12):2021-2044. https://doi.org/10.1016/S0305 $-750 \mathrm{X}(99) 00104-7$

Bennett M, Franzel S (2013) Can organic and resource-conserving agriculture improve livelihoods? A synthesis. Int J Agric Sustain 11(3):193-215. https://doi.org/10.1080/14735903.2012.724925

Biagini B, Bierbaum R, Stults M, Dobardzic S, McNeeley SM (2014) A typology of adaptation actions: a global look at climate adaptation actions financed through the Global Environment Facility. Glob Environ Change 25:97-108. https://doi.org/10.1016/J.GLOEN VCHA.2014.01.003

Biggs EM, Gupta N, Saikia SD, Duncan JMA (2018) The tea landscape of Assam: multi-stakeholder insights into sustainable livelihoods under a changing climate. Environ Sci Policy 82:9-18. https://doi.org/10.1016/j.envsci.2018.01.003

Borie M, Pelling M, Ziervogel G, Hyams K (2019) Mapping narratives of urban resilience in the global south. Glob Environ Change 54(August 2018):203-213. https://doi.org/10.1016/j. gloenvcha.2019.01.001

Cannon T (2013) Rural livelihood diversification and adaptation to climate change. In: Ensor J, Berger R, Huq S (eds) Community based adaptation to climate change: emerging lessons. Practical Action Publishing, Rugby, pp 55-75. https://doi. org/10.3362/9781780447902.004

Chang SE, Yip JZK, van Zijll de Jong SL, Chaster R, Lowcock A (2015) Using vulnerability indicators to develop resilience networks: a similarity approach. Nat Hazards 78(3):1827-1841. https://doi.org/10.1007/s11069-015-1803-x

Chen H, Zhu T, Krotta M, Calvo JF, Ganesh SP, Makot I (2013) Measurement and evaluation of livelihood assets in sustainable forest commons governance. Land Use Policy 30(1):908-914. https:// doi.org/10.1016/j.landusepol.2012.06.009

Clay N (2018) Integrating livelihoods approaches with research on development and climate change adaptation. Progress Dev Stud 18(1):1-17. https://doi.org/10.1177/1464993417735923

Dahlstrom MF (2014) Using narratives and storytelling to communicate science with nonexpert audiences. Proc Natl Acad Sci 111(Supplement_4):13614-13620. https://doi.org/10.1073/ pnas.1320645111

DANIDA (2013) QN03: multi-function storm shelters-project fact sheet. Danish International Development Agency, Copenhagen

Davies M, Béné C, Arnall A, Tanner T, Newsham A, Coirolo C (2013) Promoting resilient livelihoods through adaptive social protection: lessons from 124 programmes in South Asia. Dev Policy Rev 31(1):27-58. https://doi.org/10.111 1/j.1467-7679.2013.00600.x

Dehghani Pour M, Barati AA, Azadi H, Scheffran J (2018) Revealing the role of livelihood assets in livelihood strategies: towards enhancing conservation and livelihood development in the Hara Biosphere Reserve. Iran. Ecol Indic 94:336-347. https://doi. org/10.1016/j.ecolind.2018.05.074

Dunning KH (2020) Building resilience to natural hazards through coastal governance: a case study of Hurricane Harvey recovery in Gulf of Mexico communities. Ecol Econ 176:106759. https:// doi.org/10.1016/j.ecolecon.2020.106759

Fuhrmann E, Schiele K (2017) Combining research practices : can foreign researchers create a synthesis of scientific systems ? ASIEN German J Contemp Asia 145:5-23

Furu P, Van DK (2013) Health impacts of climate and environmental change: awareness and challenges to adaptation. In: Bruun $\mathrm{O}$, Casse $\mathrm{T}$ (eds) On the frontiers of climate and environmental 
change: vulnerabilities and adaptations in Central Vietnam. Springer, New York, pp 195-218

Geels FW, McMeekin A, Mylan J, Southerton D (2015) A critical appraisal of Sustainable Consumption and Production research: The reformist, revolutionary and reconfiguration positions. Global Environ Chang 34:1-12. https://doi.org/10.1016/j.gloen vcha.2015.04.013

Goldin J, Botha C, Koatla T, Anderson C, Owen G, Lebese A (2019) Towards a gender sensitive vulnerability assessment for climate change: Lambani, Limpopo Province, South Africa. Hum Geogr 12:1

Hopkins CR, Bailey DM, Potts T (2016) Perceptions of practitioners: managing marine protected areas for climate change resilience. Ocean Coast Manag 128:18-28. https://doi.org/10.1016/J.OCECO AMAN.2016.04.014

IPCC (2018) Special report: global warming of $1.5^{\circ} \mathrm{C}$. IPCC, Geneva

Krellenberg K, Müller A, Schwarz A, Höfer R, Welz J (2013) Flood and heat hazards in the Metropolitan Region of Santiago de Chile and the socio-economics of exposure. Appl Geogr 38:86-95. https ://doi.org/10.1016/J.APGEOG.2012.11.017

Lin K-H, Chang C-Y (2013) Everyday crises: marginal society livelihood vulnerability and adaptability to hazards. Progress Dev Stud 13:1-18. https://doi.org/10.1177/146499341201300101

Lin PSS, Liu YL (2016) Niching sustainability in an Indigenous community: protected areas, autonomous initiatives, and negotiating power in natural resource management. Sustain Sci 11(1):103113. https://doi.org/10.1007/s11625-015-0294-8

Lindkvist KB, Antelo AP (2007) Restructuring a peripheral coastal community: the case of a Galician fishing town. Int J Urban Reg Res 31(2):368-383. https://doi.org/10.111 1/j.1468-2427.2007.00731.x

Lindley S, O'Neill J, Kandeh J, Lawson N, Christian R, O’Neill M (2011) Climate change, justice and vulnerability. https://www.jrf. org.uk/report/climate-change-justice-and-vulnerability. Accessed 22 Sept 2020

Lu J, Lora-Wainwright A (2014) Historicizing sustainable livelihoods: a pathways approach to lead mining in rural central China. World Dev 62:189-200. https://doi.org/10.1016/j.worlddev.2014.05.006

Masud MM, Kari F, Yahaya SRB, Al-Amin AQ (2016) Livelihood Assets and Vulnerability Context of Marine Park Community Development in Malaysia. Soc Indic Res 125(3):771-792. https ://doi.org/10.1007/s11205-015-0872-2

McGranahan G, Balk D, Anderson B (2007) The rising tide: assessing the risks of climate change and human settlements in low elevation coastal zones. Environ Urban 19(1):17-37. https://doi. org/10.1177/0956247807076960

Narciso G (2017) Labour and migration. In: Tarp F (ed) Growth, structural transformation, and rural change in Viet Nam. Oxford University Press, Oxford, pp 138-157

Nguyen HQ, Korbee D, Ho HL, Weger J, Thi Thanh Hoa P, Thi Thanh Duyen N et al (2019) Farmer adoptability for livelihood transformations in the Mekong Delta: a case in Ben Tre province. J Environ Planning Manage 62(9):1603-1618. https://doi. org/10.1080/09640568.2019.1568768

Nightingale AJ, Eriksen S, Taylor M, Forsyth T, Pelling M, Newsham A et al (2019) Beyond Technical Fixes: climate solutions and the great derangement. Clim Dev. https://doi.org/10.1080/17565 529.2019.1624495

Pelling M, O'Brien K, Matyas D (2015) Adaptation and transformation. Clim Chang 133(1):113-127. https://doi.org/10.1007/s1058 4-014-1303-0

Quang Nam Province (2013) Quang Nam province action plan to respond to climate change (in Vietnamese). Quang Nam Province, Tam Ky

Quang Nam Province (2018) General cooperation of socio-economic reports of Quang Nam Province. Quang Nam Province, Tam Ky
Reis N (2012) Tracing and making the state. Policy practices and domestic water supply in the Mekong Delta, Vietnam. LIT, Munster

Roberts D (2010) Prioritizing climate change adaptation and local level resilience in Durban, South Africa. Environ Urban 22(2):397-413. https://doi.org/10.1177/0956247810379948

Roelen K (2018) Poor children in rich households and vice versa: a blurred picture or hidden realities? Eur J Dev Res 30(2):320-341. https://doi.org/10.1057/s41287-017-0082-7

Romero Lankao P, Qin H (2011) Conceptualizing urban vulnerability to global climate and environmental change. Curr Opin Environ Sustain 3:142-149. https://doi.org/10.1016/j.cosust.2010.12.016

Sarkki S, Ficko A, Grunewald K, Kyriazopoulos AP, Nijnik M (2017) How pragmatism in environmental science and policy can undermine sustainability transformations: the case of marginalized mountain areas under climate and land-use change. Sustain Sci 12(4):549-561. https://doi.org/10.1007/s11625-016-0411-3

Scoones I (1998) Sustainable rural livelihoods: a framework for analysis. https://opendocs.ids.ac.uk/opendocs/handle/20.500.12413 13390

Shaw J, Danese C, Stocker L (2013) Spanning the boundary between climate science and coastal communities: opportunities and challenges. Ocean Coast Manag 86:80-87. https://doi.org/10.1016/J. OCECOAMAN.2012.11.008

Shih WY, Mabon L, Puppim de Oliveira JA (2020) Assessing governance challenges of local biodiversity and ecosystem services: barriers identified by the expert community. Land Use Policy 91:104291. https://doi.org/10.1016/j.landusepol.2019.104291

Stigter CKJ, Winarto YT, Wicaksono M (2016) Science field shops: an innovative agricultural extension approach for adaptation to climate change, applied with farmers in Indonesia. Climate change management. Springer, Cham, pp 391-405. https://doi. org/10.1007/978-3-319-28591-7_21

Strauss A, Corbin J (1994) Grounded theory methodology: an overview. In: Denzin NK, Lincoln YS (eds) Handbook of qualitative research. SAGE Publications, Thousand Oaks, pp 273-285

Tanner T, Lewis D, Wrathall D, Bronen R, Cradock-Henry N, Huq S et al (2015) Livelihood resilience in the face of climate change. Nat Clim Change 5:23-26. https://doi.org/10.1038/nclimate2431

Teel TL, Anderson CB, Burgman MA, Cinner J, Clark D, Estévez RA et al (2018) Publishing social science research in Conservation Biology to move beyond biology. Conserv Biol 32(1):6-8. https ://doi.org/10.1111/cobi.13059

Tran T, James H (2017) Transformation of household livelihoods in adapting to the impacts of flood control schemes in the Vietnamese Mekong Delta. Water Resour Rural Dev 9:67-80. https://doi. org/10.1016/j.wrr.2017.04.002

United Nations Development Programme (2019) Quang Naml VIETNAM'S CLIMATE RISK INDEX. http://eng.climaterisk.org.vn/ tinh_thanh/quang-nam

Viet QT, Nauditt A, Ribbe L, Firoz ABM (2017) Biophysical and socio-economic features of the LUCCi-Project Region: The Vu Gia Thu Bon River Basin. Land use and climate change interactions in Central Vietnam: LUCCi. Springer, New York, pp 5-20

$\mathrm{Vu}$ TTL, Hoang TS (2013) The study of natural disasters variation (floods and droughts) in Quang Nam in the context of climate change. J Earth Sci 35(1):66-74 (in Vietnamese)

Walker BH (2020) Resilience: what it is and is not. Ecol Soc 25:1-3. https://doi.org/10.5751/ES-11647-250211

Wongnaa CA, Babu S (2020) Building resilience to shocks of climate change in Ghana's cocoa production and its effect on productivity and incomes. Technol Soc 62:101288. https://doi.org/10.1016/j. techsoc. 2020.101288

Yin R (1984) Case study research: design and methods. SAGE Publications Ltd, Thousand Oaks 
Yuill C, Mueller-Hirth N, Song Tung N, Thi Kim Dung N, Tram PT, Mabon L (2019) Landscape and well-being: a conceptual framework and an example. Health 23(2):122-138. https://doi. org/10.1177/1363459318804603

Zanotti L, Palomino-Schalscha M (2016) Taking different ways of knowing seriously: cross-cultural work as translations and multiplicity. Sustain Sci 11(1):139-152. https://doi.org/10.1007/s1162 5-015-0312-x
Publisher's Note Springer Nature remains neutral with regard to jurisdictional claims in published maps and institutional affiliations. 